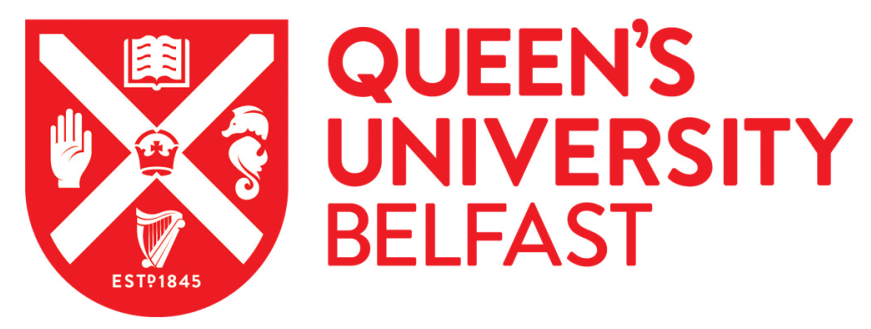

\title{
Low fruit and vegetable consumption is associated with low knowledge of the details of the 5-a-day fruit and vegetable message in the UK findings from two cross-sectional questionnaire studies
}

Appleton, K. M., Krumplevska, K., Smith, E., Rooney, C., McKinley, M. C., \& Woodside, J. V. (2017). Low fruit and vegetable consumption is associated with low knowledge of the details of the 5-a-day fruit and vegetable message in the UK findings from two cross-sectional questionnaire studies. Journal of human nutrition and dietetics : the official journal of the British Dietetic Association. https://doi.org/10.1111/jhn.12487

Published in:

Journal of human nutrition and dietetics : the official journal of the British Dietetic Association

Document Version:

Peer reviewed version

Queen's University Belfast - Research Portal:

Link to publication record in Queen's University Belfast Research Portal

\footnotetext{
Publisher rights

(c) 2017 The British Dietetic Association Ltd. This work is made available online in accordance with the publisher's policies. Please refer to any applicable terms of use of the publisher
}

\section{General rights}

Copyright for the publications made accessible via the Queen's University Belfast Research Portal is retained by the author(s) and / or other copyright owners and it is a condition of accessing these publications that users recognise and abide by the legal requirements associated with these rights.

Take down policy

The Research Portal is Queen's institutional repository that provides access to Queen's research output. Every effort has been made to ensure that content in the Research Portal does not infringe any person's rights, or applicable UK laws. If you discover content in the Research Portal that you believe breaches copyright or violates any law, please contact openaccess@qub.ac.uk. 
4

LOW FRUIT AND VEGETABLE CONSUMPTION IS ASSOCIATED WITH LOW KNOWLEDGE OF THE DETAILS OF THE 5-A-DAY FRUIT AND VEGETABLE MESSAGE IN THE UK: FINDINGS FROM TWO CROSS-SECTIONAL QUESTIONNAIRE STUDIES

KM Appleton ${ }^{1}$, K Krumplevska ${ }^{1}$, E Smith ${ }^{1}$, C Rooney ${ }^{2}$, MC McKinley ${ }^{2}$, JV Woodside ${ }^{2}$.

${ }^{1}$ Bournemouth University, UK,

${ }^{2}$ Queen's University, Belfast, UK.

Correspondence: Prof. KM Appleton, Research Centre for Behaviour Change, Department of Psychology, Faculty of Science and Technology, Bournemouth University, Poole House, Fern Barrow, Poole, BH12 5BB; tel: +44 (0)1202 965985; fax: +44 (0)1202 965413; email:

\section{k.appleton@bournemouth.ac.uk}

Short title: Knowledge of the 5-a-day FV message

\section{Acknowledgements}

This work was supported by Bournemouth University, Bournemouth, UK. There are no conflicts of interest.

\section{Authorship}

The work was conceived by KMA, with input from MCM and JVW. Materials were developed by KMA, KK, ES and CR, and the studies were undertaken by KMA, KK and ES. KMA undertook all analyses and wrote the first draft of the manuscript. All authors reviewed the draft of the manuscript and offered critical comments.

Keywords: fruit and vegetables, 5-a-day message, knowledge, questionnaires, portion sizes, variety 


\section{ABSTRACT}

Background: This project aimed to understand the details of the 5-a-day fruit and vegetable (FV) message (which foods are included, portion sizes, the need for variety, reasons for consumption) least known by UK consumers, and most associated with low FV consumption. Methods: Study 1 assessed FV consumption, knowledge of the details of the message, and relationships between these, using a short questionnaire administered face-to-face to an opportunity sample of one large UK city. Study 2 assessed the same variables using a comprehensive postal questionnaire administered across the UK to a representative population sample. Setting: UK. Results: 507 respondents completed Study 1, and 247 respondents completed study 2 . The majority of individuals in both studies were aware of the 5-a-day message and could recount this correctly. In both studies, however, knowledge of the details of the message was low, and lower knowledge was associated with lower FV consumption. Respondents had lowest knowledge of the details of the message related to portion sizes and the need for variety. However, FV consumption was not independently associated with knowledge of any one aspect of the message. Conclusions: These findings suggest that, while most of the UK population sampled were aware of the 5-a-day FV message and could recount this correctly, the details of the 5-a-day FV message were not well known, and that FV consumption was related to this knowledge. These findings suggest that strategies to increase FV consumption will benefit from increasing UK consumers' knowledge of the details of the 5-a-day FV message. 
A high consumption of fruits and vegetables (FV) is associated with reduced risk of a number of global health concerns $\left({ }^{1-10}\right)$, and as a result, the World Health Organisation (WHO) currently recommends consumption of at least $400 \mathrm{~g} \mathrm{FV/day}\left(^{3-6}\right)$. Governments around the world have operationalised and promoted the WHO recommendations as recommended consumption of a number of portions of FV per day, which in the UK is currently the consumption of five $80 \mathrm{~g}$ portions of different FV per day, or the 5-a-day FV message $\left({ }^{11,12}\right)$. Impacts of these population-wide promotional campaigns for consumption, however, appear limited $\left({ }^{13-16}\right)$. Populations seem largely aware of the campaigns $\left({ }^{13,15-19}\right)$, and message awareness has been associated with improved consumption $\left({ }^{15,17,20,21}\right)$, but despite the campaigns, population FV intakes in Europe, in the US and across the world, remain low $\left({ }^{15,22-26}\right)$.

Reasons for the low implementation of FV messages, despite awareness of the campaigns, can be suggested. For message implementation, individuals are required to understand which foods are included in the recommendations, how much of each food is required, and that a variety of these foods are required $\left({ }^{11,12}\right)$. Some researchers would also argue that knowledge of the reasons for consumption may also be necessary $\left({ }^{27,28}\right)$. Various qualitative studies suggest low understanding or confusion surrounding each of these particular aspects of the FV message $\left({ }^{27-31}\right)$. Dixon and colleagues $\left({ }^{30}\right)$ report confusion about numbers of servings and the size of servings. Dibsdall et al $\left({ }^{29}\right)$ and Carter et al $\left({ }^{27}\right)$ report confusion regarding portion sizes and the necessity and benefits of a high FV consumption. In a study by Herbert et al $\left({ }^{31}\right)$ and a study of our own $\left({ }^{28}\right)$, participants report difficulties with all three main aspects of the message (which foods are included, portion sizes, the need for variety).

Questionnaire studies also report poor knowledge specifically of portion sizes $\left({ }^{13,18-20}\right)$, but, to our knowledge, no questionnaire study to date has investigated population-wide knowledge of all four individual aspects of the 5-a-day message that may be important for message implementation (which foods are included, portion sizes, need for variety, and reasons for consumption), nor has this detailed knowledge been investigated in relation to FV consumption. Identification of which aspect/s of the 5-a-day message create the greatest confusion, and the associations between knowledge and FV consumption may demonstrate a public health education need, and allow maximal efficiency of any ensuing public health campaign. 
This project aimed to understand the aspect/s of the 5-a-day FV message of most confusion for UK consumers, and most associated with poor FV consumption. Two questionnaire studies were undertaken. Study 1 used a short seven-item questionnaire administered face-to-face to an opportunity sample on the streets of one large UK city. Study 2 used a comprehensive 10-item postal questionnaire administered across the UK, to a representative population sample. Both studies assessed FV consumption and knowledge of the 5-a-day FV message, and investigated relationships between these variables. Study 1 was intended to describe a snap-shot of self-reported FV message awareness and knowledge, free from the reporting biases of many questionnaire studies. Study 2 was intended to expand and enhance the understanding gained from Study 1. Ethical approval for both studies was gained from the Research Ethics Committee of Bournemouth University, UK, prior to commencement, and both studies were run in accordance with the Ethical Guidelines of the British Psychological Society.

\section{STUDY 1}

\section{Method}

Study 1 used a short seven-item questionnaire administered face-to-face to an opportunity sample on the streets of one large UK city.

Questionnaire: The questionnaire consisted of seven short open-response questions: one question on FV consumption, three questions on self-perceived FV knowledge and three questions on demographic characteristics. These questions were respectively: '1. How many portions of fruit and vegetables do you think you consume per day, on average?'; '2. Have you heard of the 5-a-day message?', '3. What do you think it means?', '4. Which aspect or aspects of the message do you think is/are most confusing? for example, do you know what counts as a fruit or vegetable?, or how much is needed for a portion?, or do you know you need 5 different fruits and vegetables?, or why you should be eating fruits and vegetables?'; '5. Gender?', '6. Age by decade?', and '7. How would you describe your current or most recent occupation if retired? - manual worker, non-manual worker, manager or professional or no job?'. These questions were designed to elicit simple self-report answers, reflecting each individual's consumption and knowledge as far as they were aware. Individuals who were not aware of the 5-a-day message were not asked questions 3 and 4, but were instead given the details of the message. An early version of the questionnaire asked '4. Is there anything about the message you find confusing?', thus confusion was not assumed. This question, however, elicited very little further detail when piloted to a sample of 25 respondents from the same 
source as our final sample, and so was replaced. No other amendments to the questionnaire were made following piloting.

Questionnaire Administration: Researchers administered the questionnaire face-to-face on the streets of Bournemouth, UK, to all adults who were willing to stop, able to answer the questions, and resided locally. Bournemouth is a city on the South coast of England, of diverse socio-economic status. On two separate days during June 2014, three researchers (KMA, KK, ES) were positioned on a major shopping street and near central bus stops in Bournemouth City Centre, and all passers-by between 10:00am-12:00pm and 14:00-16:00pm were asked if they would be willing to stop to answer 'a five minute survey on fruits and vegetables'. Efforts were made to ask all types of individuals, and so increase demographic variety and generalizability. All individuals who were willing and suitable completed the survey. Individuals who were not able to answer the questions due to language or cognitive difficulties, and individuals who were not local residents (e.g. holidaymakers) were thanked for their time and not questioned further.

Data Analysis: Data were entered into and analysed in SPSS. Descriptive statistics were used to describe responses to all questions. Differences between socio-demographic groups were investigated using Chi-squared tests. Impacts of message awareness and message knowledge on FV consumption were investigated using t-tests and ANOVA. There were no missing data. FV consumption data were normally distributed.

Results Complete responses were gained from 507 suitable individuals. Demographic details are given in Table 1.

FV Consumption: Mean (standard deviation) self-reported FV consumption was 3.7 (1.8) portions $/$ day, range $=0-10$ portions .

Awareness of the 5-a-day message: Of 507 individuals, 450 (88.8\%) were aware of the 5-a-day FV message, and all of these recounted the message correctly. More individuals in both the youngest and oldest age groups were unaware of the message than would be expected $\left(\chi^{2}=17.03, d f=7\right.$, 
$p=0.02)$, but no differences were found dependent on gender or occupation group (largest $\left(\chi^{2}=8.66\right.$, $d f=5, p=0.12$ ).

151

Individuals who were aware of the message reported greater FV consumption (mean (standard deviation $)=3.9(1.8)$ portions $/$ day $)$ than those not aware $($ mean $($ standard deviation $)=2.8(1.4)$ portions/day) $(t(505)=4.42, p<0.01)$.

Knowledge of the 5-a-day message: In those who were aware of the message $(n=450)$, aspects of reported no confusion (mean (standard deviation) $=4.1(1.8)$ portions/day) than in those who reported any confusion (mean (standard deviation) $=3.5(1.7)$ portions/day) $(t(431)=3.35, p<0.01)$. However, there was not one aspect of the message that caused more confusion than any other $(F(5,190)=1.26, p=0.29)$.

Table 2 about here

\section{STUDY 2}

\section{Method}

Study 2 used a comprehensive 10-item postal questionnaire administered across the UK, to a representative population sample.

Questionnaire: The questionnaire consisted of two questions on FV consumption, two questions on awareness of the 5-a-day message, four questions on knowledge of the details of the message, and two questions on demographic and lifestyle characteristics, in this order.

FV consumption was assessed using two open-response questions. The first question was used to calculate quantities of FV consumed by the respondent at various time points (before breakfast, breakfast, morning, lunch, afternoon, evening meal, evening) on a typical weekday and weekend day.

177 Amounts were reported as household measures e.g. tablespoons, and converted into ortions by a 178 researcher. Prompts were included to ensure consideration of all types of fruits and vegetables. The 179 second question asked respondents to estimate overall FV consumption using the question 'How many portions of fruit and vegetables do you think you consume per day, on average?'. The questions were used to determine calculated and estimated FV consumption respectively, and demonstrate any discrepancies between the two measures. 
To assess awareness of the message, respondents were asked two open-response questions on awareness of the 5-a-day FV message 'Are you aware of the 5-a-day FV message?' and 'What do you think it means?'.

FV knowledge was assessed in all respondents who were aware of the message, using four structured closed-response questions on: 1 ) the foods that are included in the message; 2) the portion sizes that are required for the message; 3 ) the variety that is required for the message; and 4) the reasons for FV consumption. The question on the foods that are included in the message asked respondents whether 35 commonly consumed food items $\left({ }^{23}\right)(5$ standard fruits, 5 standard vegetables, 5 processed fruits, 4 processed vegetables, 3 pulses, 5 composite dishes, 4 types of potatoes, 4 obvious errors (coffee, chocolate, jam, wine) were considered FV according to the message, using response options 'yes', 'no', 'don't know / not sure'. The question on portion sizes asked respondents to specify the number of FV portions in example quantities of 27 commonly consumed food items $\left({ }^{23}\right.$ ) (4 standard-sized fruit, 4 small fruit, 4 large fruit, 10 standard vegetables, 5 composite dishes). The question used the format 'According to the 5-a-day FV message, how much of a portion would be provided by: 1 apple?'; '1/2 banana?'; '7 cherries?'; etc. Response options were ' 0 ', ' $1 / 3^{\prime}, 1 / 2$ ', '1', '2', 'don't know / not sure'. The question on the variety required for the message asked respondents to specify the number of portions that would be provided in a day, if a person consumed 15 combinations of specified portions of FV. Eight combinations used standard single portions of FV, and seven combinations used duplicate portions of FV that should only be counted as one portion, e.g. 3 bananas. The question used the format 'According to the 5-a-day message, how many portions would be provided if a person consumed the following in a single day: 1 apple, 1 banana, and 1 glass of orange juice'?; '3 bananas'?; etc. Response options were '0', '1', '2', '3', '4', 'don't know / not sure'. The question on reasons for the message asked respondents whether 25 different health conditions were impacted by FV consumption, using response options 'yes, and there is plenty of evidence for this' (11 conditions), 'yes, possibly, but there is only a little evidence for this' (10 conditions), 'no' (4 conditions), 'don't know / not sure'. All questions were designed to allow a detailed understanding of participants' knowledge of each of the aspects of the 5-a-day FV message. For all questions, a correct response, based on current recommendations from the UK Government ${ }^{(12)}$, was scored +1 , an incorrect response was scored -1 , and 'don't know / not sure' was scored 0 . Missing values were also completed with 0 where found. Respondents who were unaware of the message were asked to bypass the knowledge questions, and complete only the following 
demographic and lifestyle questions. The complete questionnaire is provided in supplementary materials.

Demographic and lifestyle characteristics assessed were: gender, age, marital status, living status, region of residence, number of years of education, smoking habits, alcoholic drinking habits, dietary supplement taking habits, height and weight (used to calculate BMI), and month of questionnaire completion. These characteristics have all previously been associated with FV consumption and dietary knowledge $\left({ }^{13,14,16,17,20-22,25,31-33}\right)$.

Questionnaire Administration: The questionnaire was administered by post to 1200 individuals residing across the whole of the UK in 2013, and to 500 additional individuals in 2015. Names and addresses were gained for a sample of individuals representative of the UK population according to the UK 2011 census in gender, age, and region of residence from data sampling company SampleAnswers (London, UK). Questionnaires were sent to 100 individuals per month from Jan. Dec. 2013. Questionnaires were sent throughout the year to capture seasonal variation in fruit and vegetable intake, but from this initial questionnaire administration, disproportionately low responses were gained from young people and in the months of January, February, May, September and October, thus a further 100 questionnaires from the original sample and a further 10 questionnaires for Bournemouth University students were administered in these months in 2015.

Data Analysis: Data were entered into SPSS and analysed using descriptive statistics and multiple linear regression. Only questionnaires with one measure of FV consumption and less than $20 \%$ missing data were used. Missing data were completed with 'don't know / not sure' responses. Multiple linear regression models investigated associations between calculated and estimated FV consumption and knowledge of the 5-a-day FV message, where FV consumption was predicted by each aspect of message knowledge. Demographic and lifestyle characteristics were also included in all models to account for known variation between FV consumption, knowledge and various demographic and lifestyle characteristics. Scores out of 100 (percent knowledge) were used in regression models comparing knowledge of the different aspects of the message to allow comparability.

\section{Results}

248 Of 1750 questionnaires, complete responses were gained from 247 (14\%) individuals. Details of the sample are given in Table 3. The sample was representative of the UK population in terms of age 
$250\left(\chi^{2}=10.9, d f=7, p>0.05\right)$, but more females and more individuals living in the South completed the questionnaire than would have been expected (smallest $\left.\chi^{2}=11.8, d f=1, p<0.05\right)$. Number of questionnaires completed per month was even across the year $\left(\chi^{2}=15.4, d f=11, p>0.05\right)$.

FV Consumption: Mean (standard deviation) calculated FV consumption was 4.2 (2.0) portions/day, range $=0-9$ portions and mean (standard deviation) estimated FV consumption was 4.1 (1.6) portions/day, range $=0-10$ portions. These two measures were highly correlated $(r=0.53, p<0.01)$, and did not significantly differ $(\mathrm{t}(246)=0.79, \mathrm{p}=0.43$ ). Calculated $\mathrm{FV}$ consumption was higher in females than males $(\mathrm{t}(240)=2.20, \mathrm{p}=0.03)$, and was positively associated with taking vitamin supplements $(r=0.13, p=0.04)$. Estimated $F V$ consumption was higher in married than non-married individuals $(t(241)=4.53, p<0.01)$, and was associated with a higher age $(r=0.31, p<0.01)$ and taking vitamin supplements $(r=0.13, p=0.04)$.

Awareness of the 5-a-day message: Of 247 individuals, 239 (96.8\%) were aware of the 5-a-day FV message, and all those who recounted the message (209 individuals (87.4\%)) did so correctly. Differences between those who were and were not aware of the message were not investigated due to the low numbers who reported not being aware of the message and then completed the questionnaire.

Knowledge of the 5-a-day message: Number of correct responses to each of the knowledge questions is given in Table 4. Knowledge of all individual aspects of the message were correlated (smallest $r=0.16, p=0.01$ ). Percentage knowledge was higher for which foods are included $>$ reasons for consumption $>$ portion sizes $>$ the need for variety ( mallest $t(238)=6.23, p<0.01$ ).

Total knowledge was higher in married than non-married respondents $(\mathrm{t}(234)=5.42, \mathrm{p}<0.01)$, and was associated with a higher age, living further South, and smoking less (smallest $r=-0.19, p<0.01$ ). Knowledge of which foods are included was higher in females than males $(t(233)=3.70, p<0.01)$. Knowledge of portion sizes and reasons for consumption was higher in married than non-married respondents (smallest $\mathrm{t}(234)=4.28, \mathrm{p}<0.01)$, and was associated with a higher age, living further South, and smoking less (smallest $r=-0.13, p=0.04$ ). Knowledge of the need for variety was higher in married than non-married respondents (smallest $t(234)=2.17, p=0.03$ ). 
To further explore the sources of errors for each of the types of knowledge, number of correct answers to each of the individual elements were also investigated. Mean and standard deviation (st. dev.) scores out of 100 are provided in Table 5 for each question.

In relation to the question on which foods are included, more correct answers were obtained for the questions on standard fruits $>$ standard vegetables, processed fruit and obvious errors $>$ processed vegetables and pulses $>$ potatoes $>$ composite dishes (smallest $t(238)=2.85, p<0.01$ ). Considering the question on portions sizes, more correct answers were obtained for questions on standard fruits > large-sized fruit > small-sized fruit, standard vegetables and composite dishes (smallest $t(238)=3.32$, $p<0.01)$. Considering the question on the need for variety, more correct answers were given in response to the questions using standard combinations > questions using combinations involving duplicates $(t(238)=16.45, p<0.01)$. Considering the question on reasons for consumption, more correct answers were given for the questions on conditions not associated with FV > conditions definitely associated with FV consumption > conditions possibly associated with FV consumption

Table 5 about here

301

Knowledge of the message and FV consumption: Both calculated and estimated FV consumption were predicted by total number of correct answers to the knowledge questions (calculated: Beta $=0.15, p=0.06$; estimated: $B e t a=0.17, p=0.02$ ). When individual types of knowledge were assessed, both calculated and estimated FV consumption were predicted by number of correct answers to the which foods are included question (smallest Beta=0.15, $p=0.03$ ), the portion size question (smallest Beta $=0.24, p<0.01$ ) and the reasons for consumption question (smallest Beta $=0.16, p=0.03$ ), but when included together no one aspect of knowledge was more important than the other two (largest Beta $=0.18, p=0.11)$.

\section{DISCUSSION}

312 Several key findings emerge from these two studies: 1) the majority of individuals were aware of the

313 5-a-day message and could recount this correctly (Studies 1 and 2); 2) awareness of the message was

314 associated with greater FV consumption (Study 1); 3) potential confusion over the details of the 315 message was high (Study 1) and knowledge of the details of the message was low (Study 2); 4) the 316 elements of the message of greatest confusion / lowest knowledge related to portion sizes (Studies 1 and 2) and the need for variety (Study 2); 5) knowledge differed for different types of FV and 
different reasons for consumption (Study 2); 6) greater confusion / lower knowledge of the details of the message were associated with lower FV consumption (Studies 1 and 2); but 7) no one element of confusion or knowledge was associated with FV consumption (Studies 1 and 2).

Regarding awareness, high awareness of the 5 -a-day message has been reported in other populations $\left({ }^{13,15}\right)$. We suspect that the relatively higher rates of awareness reported in study 2 may be due to a reporting bias, where individuals who were unaware of the message were simply less likely to return the (mostly incomplete) questionnaire and that population rates of awareness of the 5-a-day message are likely to be closer to $85 \%$ of the population as in Study 1. Levels of awareness of around $80-85 \%$ of the population have been reported previously both in the UK $\left({ }^{17,18}\right)$ and elsewhere $\left({ }^{13,16,27}\right)$. This awareness is likely to have resulted from a variety of sources including Government campaigns, e.g. Change for Life; TV, billboard and magazine advertising; local health promotion campaigns in GP surgeries, schools and workplaces; and advertising campaigns in supermarkets and on food packaging $\left({ }^{11,13-16,18}\right)$. An association between awareness of the message or a FV message campaign and higher FV consumption has also previously been reported $\left({ }^{15-17,20,21}\right)$.

High confusion surrounding the message and low knowledge of the details of the message have also previously been reported. Qualitative studies suggest poor knowledge in the majority of participants $\left({ }^{27-31}\right)$, and the few questionnaire studies that have been conducted suggest poor knowledge across populations $\left({ }^{13,18-20}\right)$.

Particular confusion over portion sizes has also previously been reported $\left({ }^{18,19,27,28,30}\right)$, and both qualitative and quantitative earlier studies suggest particular difficulties with smaller FV items, vegetables and composite dishes as was found in our data $\left({ }^{19,20.28,31}\right)$. Errors in particular are suggested to be more likely, where different portion sizes are used for different FV items $\left({ }^{28}\right)$, and this is particularly the case for small items. Difficulties with estimating portions of vegetables and the components of composite dishes may also arise as a result of their usual small contribution to a portion. Greater ease has previously been noted where one portion is equivalent to one 'whole' and 'discrete' FV item $\left({ }^{28,31}\right)$.

Confusion over portion sizes was also, in some individuals, related to confusion over the number of servings required: in the UK, some individuals reported believing the 5 -a-day message relates to 5 portions of fruit and 5 portions of vegetables per day $\left({ }^{28}\right)$, as was also found here in Study 1 , and in Australia, where the FV message specifies 2 fruits and 5 vegetables, individuals report confusion as 
to whether they should consume 5 different vegetables, 5 cups of vegetables, or 5 plates of vegetables, while the actual recommendation is 5 half cups $\left({ }^{27}\right)$.

Qualitative studies have also reported a lack of understanding over the need for variety. Several studies report a failure among participants to appreciate the need for a variety of FV for health benefits $\left({ }^{20,28,29,31}\right)$, or the need even for fruits and vegetables $\left({ }^{31}\right)$. Correct answers were particularly low in our data for the combinations containing duplicates compared to those using single items. The low knowledge of variety in our study may also relate to low knowledge of portion sizes, as variety was assessed by asking for number of portions consumed in a day, so some (simple) portion size knowledge was required.

Limited studies have also reported a positive association between knowledge of portion sizes and FV consumption $\left({ }^{20}\right)$. Nutritional knowledge is a known predictor of healthy eating, including FV consumption $\left({ }^{21,32-36}\right)$, and studies of other specific aspects of dietary knowledge have been associated with specific dietary practices and healthier diets $\left({ }^{34-36}\right)$.

Interestingly, in our study, while total knowledge of the 5-a-day FV message was positively associated with FV consumption, knowledge of no one particular aspect of the message was more important than any other aspect. These findings may plausibly suggest that it is not one particular type of knowledge that is important, but the combination of all types of knowledge that results in a higher FV consumption. Thus while consumers can highlight confusion over portion sizes, and while portion size knowledge can be related to FV consumption, knowledge on portion sizes is only part of the picture, and the other elements of the message should not be ignored. Reassuringly, these findings might also suggest that general knowledge of all elements of the message may be more beneficial for consumption than detailed knowledge of any one aspect, or alternatively, that different consumers may struggle with different elements of the message. In both cases, it would appear that as a population, education is still needed on all elements of the 5-a-day message.

Appropriate routes for this education can be suggested. Some Government campaigns have been revised to specify number of fruits and vegetables separately to address the need for variety. For example in the Netherlands, consumers are asked to aim for $2+2$ fruits and vegetables, and in Australia, consumers are asked to aim for $2 \& 5$ fruits and vegetables respectively $\left({ }^{1}\right)$. In New Zealand, the campaign logo depicts a hand as a suggestion for portion size $\left({ }^{13}\right)$. Preferences for portion size measures (grams, handfuls, cups, spoons), however have been found to vary widely $\left({ }^{13,28,31}\right)$. 
Alternatively, more detailed knowledge may be provided via campaign and promotional materials, such as posters, leaflets or magazine articles $(11,13-16,18,28)$, and through increased information on food packaging and menus $\left({ }^{28}\right)$. Other suggestions largely incorporate knowledge as part of a wider intervention $\left({ }^{37-39}\right)$. These types of intervention, however, tend to be more complex and individually based, and while success on an individual basis is often reported $\left({ }^{37-39}\right)$, these types of intervention can be costly and time-consuming to implement and so impractical on a population-wide basis $\left({ }^{37}\right)$.

Nonetheless, the argument for increased FV intakes on a population-wide basis is compelling. Recent estimates suggest that $1.8 \%$ total global burden of disease $\left({ }^{40}\right)$ and approximately 16 million global disability adjusted life years (DALYs) $\left({ }^{40}\right)$ can be attributed to inadequate FV intakes. Estimates for the UK suggest 2-7\% burden of disease (assessed using DALYs) $\left({ }^{41}\right.$ ) from inadequate FV intakes, and that an increase in consumption of one additional FV portion/day across the population could reduce risk of $\mathrm{CHD}$ incidence and stroke by approximately 4 and $5 \%$ respectively $\left({ }^{42,43}\right)$. We make no suggestion here for the ideal route for increasing knowledge of the details of the 5-a-day FV message on a population-wide basis. Further work is clearly needed. We also make no suggestion that increasing knowledge of the details of the 5-a-day message may increase FV consumption more effectively or efficiently than other (non-knowledge) types of intervention. Interventions aiming to improve taste or motivation, and interventions using environmental changes and 'nudging' principles are also demonstrating some success $\left({ }^{\text {e.g.1,44-46 }}\right)$.

The strengths of our research include the comparability of the results from the two studies, our consideration of knowledge in relation to the 5-a-day FV message and use of detailed measures of knowledge, and our consideration also of FV consumption. Socio-demographic associations with FV consumption are also similar to those found in other studies of the UK population $\left(^{(e . g .22,23}\right)$. Our Study 1 may be confounded to some extent by social desirability $\left({ }^{15}\right)$, but, given the detail required, this is less likely in Study 2. Conversely, study 2 may be confounded by possible responder bias $\left({ }^{19}\right)$, but this is unlikely to have affected the results of Study 1. Females and individuals living in the South of the UK were over-represented in our final sample, limiting the conclusions that can be drawn about the UK population as a whole. Both females and those living in the South (as a result of a warmer climate and higher affluence) are also more likely to consume FV and more likely to hold higher FV knowledge $\left({ }^{22,23,32,33}\right)$, but we have no reason to believe the associations between these variables would differ by gender or region. Both studies are limited by the use of self-report measures for FV 
consumption, and poor knowledge will result in inaccuracies. Self-report measures of dietary intake, however, are necessary and commonly used in questionnaire studies such as these $\left({ }^{13,18-22,45,46}\right)$.

\section{CONCLUSIONS}

These findings suggest that, while most of the UK population are aware of the 5-a-day FV message and can recount this correctly, the details of the message are not well known, and that FV consumption is related to this knowledge. These findings suggest that strategies to increase FV consumption will benefit from increasing consumers' knowledge of the details of all aspects of the 5a-day FV message. The findings also suggest that greatest confusion and least knowledge surrounds the details of portion sizes and the need for variety, although knowledge of these details does not explain FV consumption.

\section{Acknowledgements}

This work was supported by Bournemouth University, Bournemouth, UK. There are no conflicts of interest. The work was conceived by KMA, with input from MCM and JVW. Materials were developed by KMA, KK, ES and CR, and the studies were undertaken by KMA, KK and ES. KMA undertook all analyses and wrote the first draft of the manuscript. All authors reviewed the draft of the manuscript and offered critical comments.

\section{Transparency statement}

The lead author affirms that this manuscript is an honest, accurate, and transparent account of the study being reported. The reporting of this work is compliant with STROEBE guidelines. The lead author affirms that no important aspects of the study have been omitted and that any discrepancies from the study as planned have been explained.

\section{REFERENCES}

1. Appleton KM, Hemingway A, Saulais L, et al. Increasing vegetable intakes: Rationale and systematic review of published interventions. Eur J Nutr. 2016;55:869-896 2. Woodside JV, Young IS, McKinley MC. Fruits and vegetables: measuring intake and encouraging increased consumption. Proc Nutr Soc. 2013;72:236-45. 3. World Health Organisation. Diet, nutrition and the prevention of chronic diseases. WHO technical report series 797, Geneva: WHO, 1990.

4. World Health Organisation. The World Health Report: Reducing risks, promoting health. Geneva: WHO, 2002. 

Joint FAO/WHO Expert Consultation. WHO Technical Report Series, No. 916, Geneva: WHO, 2003.

454 6. World Health Organisation. Fruit and Vegetables for Health Report of a Joint FAO/WHO

455 Workshop, 1-3 September 2004, Kobe, Japan. Geneva: WHO, 2005.

456 7. Bazzano LA, He J, Ogden LG, et al. Fruit and vegetable intake and risk of cardiovascular disease in

457 US adults: The first National Health and Nutrition Examination Survey Epidemiologic Follow-up 458 Study. Am J Clin Nutr. 2002;76:93-99.

459 8. Tohill BC. Dietary intake of fruit and vegetable and management of body weight. Background 460 paper for the Joint FAO/WHO Workshop of fruit and vegetables for health. 1-3 September, 2004, 461 Kobe, Japan. Geneva: WHO, 2005.

462 9. Harding AH, Wareham NJ, Bingham SA, et al. Plasma vitamin C level, fruit and vegetable 463 consumption, and the risk of new-onset Type 2 Diabetes Mellitus. Arch Int Med. 2008; 168:1493-99 464 10. Riboli E, Norat T. Epidemiologic evidence of the protective effect of fruit and vegetables on 465 cancer risk. Am J Clin Nutr. 2003;78(suppl):559S-69S.

466 11. Cullum A. Increasing fruit and vegetable consumption: the 5 A DAY programme. Nutr Bulletin. $467 \quad 2003 ; 28: 159-63$.

468 12. National Health Service. 5-a-day campaign. Website:

469 http://www.nhs.uk/livewell/5aday/pages/5adayhome.aspx/. Accessed $9^{\text {th }}$ June, 2010.

470 13. Ashfield-Watt PAL. Fruit and vegetables, 5+ a day: are we getting the message across? Asia Pac J

471 Clin Nutr. 2006;15:245-52.

472 14. Capacci S, Mazzocchi M. Five-a-day, a price to pay: An evaluation of the UK program impact 473 accounting for market forces. J Health Econ. 2011;30:87-98.

474 15. Dixon H, Borland R, Segan C, et al. Public reaction to Victoria's "2 fruit ' $n$ ' 5 veg every day" 475 campaign and reported consumption of fruit and vegetables. Prev Med. 1998;27:572-82.

476 16. Pollard CM, Miller MR, Daly AM, et al. Increasing fruit and vegetable consumption: success of the 477 Western Australian Go for 2\&5 campaign. Pub Health Nutr. 2007;11:314-320.

478 17. Appleton KM, McGill R, Neville C, Woodside JV. Barriers to increasing fruit and vegetable intakes 479 in the older population of Northern Ireland: Low levels of liking and low awareness of current 480 recommendations. Pub Health Nutr. 2010;13:514-521.

481 18. Buyuktuncer Z, Kearney M, Ryan CL, et al. Fruit and vegetables on prescription: $A$ brief 482 intervention in primary care. J Hum Nutr Diet. 2014;27:186-93.

483 19. Glasson C, Chapman K, James E. Fruit and vegetables should be targeted separately in health 484 promotion programmes: differences in consumption levels, barriers, knowledge and stages of 485 readiness for change. Pub Health Nutr. 2011;14:694-701. 

Health Nutr. 2008;12:637-43.

21. Erinosho TO, Moser RP, Oh AY, et al. Awareness of the Fruits and Veggies - More Matters campaign, knowledge of the fruit and vegetable recommendation, and fruit and vegetable intake of adults in the 2007 Food Attitudes and Behaviors (FAB) Survey. Appetite 2012;59:155-160. 22. Appleton KM, McGill R, Woodside JV. Fruit and vegetable consumption in older people in Northern Ireland: levels and patterns. Brit J Nutr. 2009;102:949-953. 23. Bates B, Lennox A, Swan G. National Diet Nutrition Survey: Headline results for year 1 of the rolling programme (2008/2009), London: Food Standards Agency, 2009. 24. European Food Safety Authority. Concise Database summary statistics - Total population. Available at: http://www.efsa.europa.eu/en/datexfoodcdb/datexfooddb.htm. Accessed $10^{\text {th }}$ March, 2015. 25. O'Brien MM, Kiely M, Galvin M, Flynn A. The importance of composite foods for estimates of vegetable and fruit intakes. Pub Health Nutr. 2003;6:711-726. 26. United States Department of Agriculture.

501 http://www.ers.usda.gov/Data/FoodConsumption/FoodAvailSpreadsheets.htm. Accessed $10^{\text {th }}$ 502 March, 2015.

503 27. Carter OBJ, Pollard CM, Atkins JFP, et al. 'We're not told why - we're just told': qualitative reflections about the Western Australian Go for $2 \& 5$ fruit and vegetable campaign. Pub Health Nutr. 2010;14:982-8. 28. Rooney C, McKinley MC, Appleton KM, et al. How much is '5-a-day'?: A qualitative investigation into consumer understanding of fruit and vegetable intake guidelines. J Hum Nutr Diet. 2017;30:105113.

29. Dibsdall LA, Lambert N, Frewer LJ. Using interpretative phenomenology to understand the foodrelated experiences and beliefs of a select group of low-income UK women. J Nutr Educ Behav. 2002;34:298-309.

512 30. Dixon H, Mullins R, Wakefield M, Hill D. Encouraging the consumption of FVs by older

513 Australians: An experiential study. J Nutr Educ Behav. 2004;36:245-249.

514 31. Herbert G, Butler L, Kennedy O, Lobb A. Young UK adults and the 5 A DAY campaign: Perceived 515 benefits and barriers to eating more fruits and vegetables. Int J Cons Studies. 2010;34:657-64.

516 32. Parmenter K, Waller J, Wardle J. Demographic variation in nutrition knowledge in England.

517 Health Educ Res. 2000;15:163-74.

518 33. Wardle J, Parmenter K, Waller J. Nutrition knowledge and food intake. Appetite 2000;34:269-75. 
34. Guillaumie L, Godin G, Vézina-Im LA. Psychosocial determinants of fruit and vegetable intake in adult population: a systematic review. Int J Behav Nutr Physical Activity 2010;7:12. 35. Shaikh AR, Yaroch AL, Nebeling L, et al. Psychosocial predictors of fruit and vegetable consumption in adults: A review of the literature. Am J Prev Med. 2008;34:535-43.

36. Spronk I, Kullen C, Burdon C, O'Connor H. Relationship between nutrition knowledge and dietary intake. Br J Nutr. 2014;111:1713-26.

37. Michie S, Abrahan C, Whittington C, McAteer J. Effective techniques in healthy eating and physical activity interventions: A meta-regression. Health Psychol. 2009;28:690-701.

38. Pomerleau J, Lock K, Knai C, McKee M. Interventions designed to increase adult fruit and vegetable intake can be effective: A systematic review of the literature. J Nutr. 2005;135:2486-95. 39. Thomson CA, Ravia J. A systematic review of behavioural interventions to promote intake of fruit and vegetables. J Am Diet Assoc. 2011;111:1523-1535.

40. Lock K, Pomerleau J, Causer L, et al. The global burden of disease attributable to low consumption of fruit and vegetables: Implications for the global strategy on diet. Bull World Health Organization. 2005;83:100-108.

41. Murray CJL, Richards MA, Newton JN, et al. UK health performance: Findings of the Global Burden of Disease Study 2010, The Lancet. 2013;381:997-1020.

42. Dauchet L, Amouyel P, Dallongeville J. Fruit and vegetable consumption and risk of stroke: $A$ meta-analysis of cohort studies. Neurology. 2005;65:1193-7.

43. Dauchet $L$, Amouyel P, Hercberg S, Dallongeville J. Fruit and vegetable consumption and risk of coronary heart disease: A meta-analysis of cohort studies. J Nutr. 2006;136:2588-93.

44. Appleton KM. Greater fruit selection following an appearance-based compared to a health-based health promotion poster. Journal of Public Health. 2016;38:731-38.

45. Rasmussen RF, Skov LR, Olsen A, et al. Comparison of three nudge interventions (priming, default option, and perceived variety) to promote vegetable consumption in a self-service buffet setting. Plos One, in press.

46. Saulais L, Appleton KM, Perez Cueto FJA, et al. Using default options to nudge vegetable consumption: An experimental investigation of status quo bias in food choices. Food Policy, in press. 47. Thompson FE, Willis GB, Thompson OM, Yaroch AL. The meaning of 'fruits' and 'vegetables'. Pub Health Nutr. 2011;14:1222-8.

48. Wolfe WS, Frongill EA, Cassano PA. Evaluating brief measures of fruit and vegetable consumption frequency and variety. J Am Diet Assoc. 2001;101:311-8. 
Table 1: Demographic details of the sample gained for Study 1 ( $N=507)$.

552

\begin{tabular}{|l|l|l|}
\hline Characteristic & Description & Number (\%) of respondents \\
\hline Gender & Male & $190(37.5 \%)$ \\
\hline Age & Female & $314(61.9 \%)$ \\
\hline & Individuals aged <20 years & $165(32.5 \%)$ \\
\hline & Individuals aged 20-29 years & $13(2.6 \%)$ \\
\hline & Individuals aged 30-39 years & $67(13.2 \%)$ \\
\hline & Individuals aged 40-49 years & $55(10.8 \%)$ \\
\hline & Individuals aged 50-59 years & $69(13.6 \%)$ \\
\hline & Individuals aged 60-69 years & $61(12.0 \%)$ \\
\hline & Individuals aged 70-79 years & $48(9.5 \%)$ \\
\hline & Individuals aged $\geq 80$ years & $26(5.1 \%)$ \\
\hline & Professionals & $93(18.3 \%)$ \\
\hline & Skilled non-manual workers & $115(22.7 \%)$ \\
\hline & Skilled manual workers & $80(15.8 \%)$ \\
\hline & Non-skilled manual workers & $73(12.4 \%)$ \\
\hline & Students & $118(23.3 \%)$ \\
\hline & Unemployed & $37.3 \%)$ \\
\hline
\end{tabular}

553 
Table 2: Aspects of the FV message of greatest confusion, in those who were aware of the message $(n=450)$

557

\begin{tabular}{|l|l|}
\hline Aspect of the message & Number (\%) of respondents ${ }^{\#}$ \\
\hline Confused by which foods count as fruit and vegetables & $23(5.0 \%)$ \\
\hline Confused by how much was needed for a portion & $135(29.9 \%)$ \\
\hline Confused by the need for 5 different fruits and vegetables & $27(5.9 \%)$ \\
\hline Confused by the reasons for consuming fruit and vegetables & $10(2.2 \%)$ \\
\hline Thought the number 5 referred to 5 fruits and 5 vegetables per day & $4(0.9 \%)$ \\
\hline Thought the number was more or less than 5 & $4(0.9 \%)$ \\
\hline Not confused by any aspect of the message & $240(53.3 \%)$ \\
\hline
\end{tabular}

\#Percentages do not total $100 \%$ because multiple responses were allowed. 
Table 3: Demographic details of the sample for Study $2(n=247)$.

\begin{tabular}{|l|l|l|}
\hline Characteristic & Description & Number (\%) of respondents \\
\hline Gender & Males & $80(32.4 \%)$ \\
\hline & Females & $167(67.6 \%)$ \\
\hline Age & Individuals aged < 20 years & $27(10.9 \%)$ \\
\hline & Individuals aged 20-29 years & $53(21.4 \%)$ \\
\hline & Individuals aged 30-39 years & $30(12.1 \%)$ \\
\hline & Individuals aged 40-49 years & $24(9.7 \%)$ \\
\hline & Individuals aged 50-59 years & $32(13.0 \%)$ \\
\hline & Individuals aged 60-69 years & $36(14.6 \%)$ \\
\hline Marital status & Individuals aged 70-79 years & $25(10.1 \%)$ \\
\hline & Individuals aged $\geq 80$ years & $11(4.4 \%)$ \\
\hline Living status & Married & $103(41.7 \%)$ \\
\hline & Single / Divorced / Separated & $140(56.7 \%)$ \\
\hline Region of residence & Living alone & $42(17.0 \%)$ \\
\hline & Lving with others & $201(81.4 \%)$ \\
\hline & Scotland and Northern Ireland & $17(6.9 \%)$ \\
\hline & North England & $22(8.9 \%)$ \\
\hline & South & $46(18.6 \%)$ \\
\hline & & $158(64.0 \%)$ \\
\hline
\end{tabular}

562

563 
Table 4: Mean, standard deviation (st. dev.) range, and maximum possible (max. poss.) number of correct answers to the questions on 1) what was included in the message; 2) portion sizes; 3) the need for variety; and 4) reasons for consumption - Study 2 ( $N=239$ ). Mean and standard deviation (st. dev.) scores out of 100 have also been calculated to allow comparison between knowledge of the different aspects of the message.

570

\begin{tabular}{|l|l|l|l|l|}
\hline & Mean $^{\#}$ & $\begin{array}{l}\text { St. } \\
\text { dev. }\end{array}$ & $\begin{array}{l}\text { Min., } \\
\text { Max. }\end{array}$ & $\begin{array}{l}\text { Min. } \\
\text { Max. } \\
\text { poss. }\end{array}$ \\
\hline $\begin{array}{l}\text { Which foods are included in the 5-a-day FV message - } \\
\text { scores (scores out of 100) }\end{array}$ & $\begin{array}{l}20.8 \\
(59.4)^{a}\end{array}$ & $\begin{array}{l}6.9 \\
(19.6)\end{array}$ & $-17,35$ & $-35,35$ \\
\hline $\begin{array}{l}\text { Portion sizes for the 5-a-day FV message - scores (scores } \\
\text { out of 100) }\end{array}$ & $\begin{array}{l}3.9 \\
(14.4)^{c}\end{array}$ & $\begin{array}{l}8.6 \\
(31.7)\end{array}$ & $-19,18$ & $-27,27$ \\
\hline $\begin{array}{l}\text { Need for variety in the 5-a-day FV message - scores } \\
\text { (scores out of 100) }\end{array}$ & $\begin{array}{l}-0.6 \\
(-4.0)^{d}\end{array}$ & $\begin{array}{l}6.0 \\
(40.0)\end{array}$ & $-13,15$ & $-15,15$ \\
\hline Reasons for consumption - scores (scores out of 100) & 7.0 & 7.2 & $-15,20$ & $-25,25$ \\
\hline Total & $(27.6)^{b}$ & $(28.9)$ & & \\
\hline
\end{tabular}




\begin{tabular}{|l|l|l|}
\hline Which foods are included in the 5-a-day FV message & Mean $^{\#}$ & St. dev. \\
\hline Standard fruit, e.g. apple (5 items) & $97.3^{\mathrm{a}}$ & 15.6 \\
\hline Standard vegetables, e.g. green beans & $86.8^{\mathrm{b}}$ & 24.7 \\
\hline Processed fruit, e.g. tinned pineapple & $83.8^{\mathrm{b}}$ & 31.2 \\
\hline Processed vegetables, e.g. fried onion & $42.1^{\mathrm{c}}$ & 48.0 \\
\hline Pulses, e.g. lentils & $38.0^{\mathrm{c}}$ & 60.9 \\
\hline $\begin{array}{l}\text { Composite dishes, e.g. stew (1/3 meat, 1/3 onions and root vegetables, } \\
\text { 1/3 potatoes) }\end{array}$ & $-0.1^{\mathrm{e}}$ & 60.1 \\
\hline Potatoes, e.g. chips & $27.5^{\mathrm{d}}$ & 57.6 \\
\hline Obvious errors, e.g. wine & $87.1^{\mathrm{b}}$ & 24.7 \\
\hline Portion sizes for the 5-a-day FV message & & \\
\hline Standard fruit, e.g. one apple & $44.2^{\mathrm{a}}$ & 29.8 \\
\hline Small-sized fruit, e.g. 7 cherries & $8.9^{\mathrm{c}}$ & 54.8 \\
\hline Large sized fruit, e.g. quarter of a melon & $19.9^{\mathrm{b}}$ & 41.8 \\
\hline Standard vegetables, e.g. one tablespoon of green beans & $4.6^{\mathrm{c}}$ & 33.3 \\
\hline $\begin{array}{l}\text { Composite dishes, e.g. 3 tablespoons of stew (1/3 meat, 1/3 onions and } \\
\text { root vegetables, 1/3 potatoes) }\end{array}$ & $1.1^{\mathrm{c}}$ & 49.9 \\
\hline Need for variety in the 5-a-day FV message & & \\
\hline $\begin{array}{l}\text { 8 straightforward combinations, e.g. one apple, one banana, one glass of } \\
\text { fruit juice }\end{array}$ & $16.3^{\mathrm{a}}$ & 47.2 \\
\hline 7 combinations involving duplicates, e.g. 3 bananas & $-27.1^{\mathrm{b}}$ & 57.2 \\
\hline Reasons for consumption & $29.4^{\mathrm{b}}$ & 37.2 \\
\hline Conditions definitely associated with FV consumption, e.g. stroke & $21.1^{\mathrm{c}}$ & 40.3 \\
\hline Conditions possibly associated with FV consumption, e.g. sunburn & 48.4 \\
\hline Conditions not associated with FV consumption, e.g. measles & $38.4^{\mathrm{a}}$ \\
\hline
\end{tabular}

